\title{
Optimum synthesis of $\mathrm{CuO}$ nanoparticles with the highest antifungal activity against oral pathogen Candida albicans
}

\author{
Mohammad Moslem Imani ${ }^{1}$, Mohsen Safaei ${ }^{*}$, Hedaiat Moradpoor ${ }^{3}$, Razieh Rezaei ${ }^{2,4}$, Amin Golshah ${ }^{1}$, Farzad Rezaei ${ }^{5}$, \\ Ladan Jamshidy ${ }^{3}$ \\ ${ }^{1}$ Department of Orthodontics, School of Dentistry, Kermanshah University of Medical Sciences, Kermanshah, Iran. \\ ${ }^{2}$ Advanced Dental Sciences Research Laboratory, School of Dentistry, Kermanshah University of Medical Sciences, Kermanshah, Iran. \\ ${ }^{3}$ Department of Prosthodontics, School of Dentistry, Kermanshah University of Medical Sciences, Kermanshah, Iran. \\ ${ }^{4}$ Medical Biology Research Center, Kermanshah University of Medical Sciences, Kermanshah, Iran. \\ ${ }^{5}$ Department of Oral and Maxillofacial Surgery, School of Dentistry, Kermanshah University of Medical Sciences, Kermanshah, Iran.
}

\begin{tabular}{l}
\hline ARTICLE INFO \\
\hline Received on: 08/02/2019 \\
Accepted on: 26/11/2019 \\
Available online: 05/02/2020 \\
\hline Key words: \\
Antifungal activity, CuO \\
nanoparticles, oral pathogen, \\
Candida albicans, Taguchi \\
method, biomedical \\
application.
\end{tabular}

\begin{abstract}
This research was aimed to optimize the synthesis of copper oxide $(\mathrm{CuO})$ nanoparticles with the highest antifungal properties against Candida albicans as an oral fungal pathogen. To this end, nine experiments involving different synthesis conditions were designed using the Taguchi method and the copper oxide nanoparticles synthesized by coprecipitation method. The antifungal activity of synthesized nanoparticles against C. albicans was evaluated using the colony forming unit and disk diffusion methods. According to the results, the synthesized copper oxide nanoparticles under the five experimental conditions $\left(\mathrm{CuCl}_{2} 0.1 \mathrm{M}, \mathrm{NaOH} 0.1 \mathrm{M}\right.$, and a 75 minutes stirring time) showed the highest antifungal activity against $C$. albicans $(71.72 \%)$. The optimization results demonstrated that all three studied factors were effective in improving the antifungal activity of copper oxide nanoparticles and the antifungal activity in the proposed conditions can be improved by $77.85 \%$. The synthesis of nanoparticles in optimal conditions confirmed the improved antifungal activity of the nanoparticles. The results of this study proved that $\mathrm{CuO}$ nanoparticles have a potential ability as an antifungal agent against oral fungal pathogens of C. albicans.
\end{abstract}

\section{INTRODUCTION}

Tremendous progress has been achieved in the treatment of diseases over the recent decades. However, we still struggle with challenges in the treatment of certain diseases such as cancers (Mozaffari et al., 2016; 2017), chronic pains (Sharifi et al., 2017), autoimmune diseases (Mozaffari et al., 2018), and microbial infections (Safaei and Taran, 2017a). It is believed that the microbial pathogens found in the oral cavity, which produce biofilms, are the main cause of dental caries and the destruction of enamel (Struzycka, 2014). The uncontrolled increase in the amount of oral microbial agents' results in the penetration into the dentin

\footnotetext{
*Corresponding Author

Mohsen Safaei, Advanced Dental Sciences Research Laboratory, School of Dentistry, Kermanshah University of Medical Sciences, Kermanshah, Iran. E-mail:mohsen_safaei@yahoo.com
}

and tooth pulp infection, causing severe pain, tooth pulp necrosis, loss of teeth, and systemic infections (Cura et al., 2012; Farges et al., 2015). Untreated dental caries is seen as a major global challenge in many countries (Frencken et al., 2017). Dental caries is considered as the fourth chronic disease with costly treatment according to the World Health Organization, which can cause severe pain and oral infections if it is left untreated (Petersen et al., 2005). Many dental caries cases are not treated in many developing countries and a large number of people in the community suffer from their complications. Untreated dental caries can make changes in the body's health status, quality of life, patterns of growth, and the performance of individuals (Fallahi et al., 2014).

Given the priority of prevention to treatment, making efforts to identify and generalize the dental caries prevention methods seems necessary. The use of antimicrobial mouthwashes is one of the most important ways to prevent caries, which can be effective in controlling tooth decay. Commercial antiplaque compounds cause a change in the bacterial flora of the mouth 
and thus induce the growth of opportunistic pathogens, including Candida albicans (Goes et al., 2016). Hence, it seems absolutely essential to look for an alternative antimicrobial agent with minimal side effects. Thus, the use of nanotechnology as a new human knowledge appears to be important for the production of antimicrobial mouthwashes with higher quality and efficiency for the treatment and prevention of dental caries.

In general, nanomaterials have specific properties in comparison to other materials. When the material size is reduced to below $100 \mathrm{~nm}$, they exhibit different properties based on quantum mechanisms (Safaei et al., 2017). Nanoparticles can be synthesized and produced from a wide range of materials, the most common of which are silicates, non-oxide ceramics, and metal oxides. Metal oxides have come recently to the focus of attention due to their sustainability in different conditions, and safety for humans and the environment (Zhang et al., 2007). Proper antimicrobial properties at low concentrations are among the most important properties of nano metal oxides. Some of them, like silver oxide, titanium oxide, zinc oxide, magnesium oxide, iron oxide, and copper oxide, exhibit favorable antimicrobial properties (Dizaj et al., 2014; Zhu and Liao, 2015).

Copper oxide nanoparticles are one of the most important transition metals oxides due to their prominent properties. The copper oxide nanoparticle is widely used nowadays due to high biocompatibility, non-toxicity, and easy preparation of this nanoparticle (Lanje et al., 2010). The copper oxide nanoparticle is a highly regarded metal nanoparticle due to a wide range of activities against the pathogens. The copper capability in electron donation and acceptance is an important factor in providing its antimicrobial properties. Thus, it has a high ability to catalyze oxidation and reduction reactions. The concentration of copper ions, the type of microorganism, and environmental conditions affect the performance of copper oxide nanoparticles. The copper oxide nanoparticles cause cell death by binding to the cell wall, the active site of enzymes, and interfering with the nucleic acids (Safaei et al., 2019; Sata et al., 2002).

Since the optimum synthesis of $\mathrm{CuO}$ nanoparticles has not been so far studied as a fungicide agent with the highest antifungal activity. The objective of this study is to optimize the synthesis of copper oxide nanoparticles with the highest antifungal activity using the coprecipitation method and evaluate their antifungal activity by using the colony forming unit (CFU) and disk diffusion methods against oral pathogen C. albicans.

\section{MATERIALS AND METHODS}

\section{Synthesis of $\mathrm{CuO}$ nanoparticles}

Applying the Taguchi method and Qualitek-4 software, nine tests containing different ratios of copper chloride and sodium hydroxide and various stirring times were designed to optimize the synthesis of copper oxide nanoparticles. The copper oxide nanoparticles were synthesized using the coprecipitation method. In this method, the solutions of copper chloride and sodium hydroxide $(0.1 \mathrm{M})$ were prepared at a volume of $100 \mathrm{ml}$ separately and stirred for 45,60 , and 75 minutes to become completely homogeneous. Then, the containers containing copper chloride solution were placed on a magnetic stirrer while adding the sodium hydroxide solution drop by drop to them until the formation of a dark precipitate. At this time, the sediments obtained were filtered using centrifuges and rinsed thrice with deionized water to remove the impurities. The resulted precipitate was dried in an oven at $80^{\circ} \mathrm{C}$ for 24 hours. Finally, it was calcined in air at $450^{\circ} \mathrm{C}$ for 4 hours in order to obtain copper oxide nanoparticles powder.

\section{Antifungal activity}

CFU and disk diffusion methods were used to examine the rate of antifungal activity of the synthesized nanoparticles against $C$. albicans. The $C$. albicans standard strain (ATCC 10231) was obtained from the Iranian Scientific and Industrial Research Organization and was cultured on the Sabouraud dextrose agar (SDA) media for 24 hours at $30^{\circ} \mathrm{C}$. Then, the fungal suspensions $\left(1-5 \times 10^{6} \mathrm{CFU} / \mathrm{ml}\right)$ along with $200 \mu \mathrm{l}$ of the studied nanoparticles under different conditions were shaken for 6 hours inside an incubator shaker $(140 \mathrm{rpm})$ at $30^{\circ} \mathrm{C}$. The fungal suspensions were diluted 10 times using the dilution series for the CFU test. The resulted solutions were cultured on SDA culture medium for each dilution and the plates were placed in an incubator $30^{\circ} \mathrm{C}$ for 24 hours. After incubation, the number of colonies grown in each plate was counted and their mean value was calculated. All the experiments of this stage were performed thrice with three replicates. In the disk diffusion method, after preparing the homogenous suspensions from $C$. albicans, they were transferred into the SDA culture medium and fully cultured by a swab. The disks containing $200 \mu$ l of nanoparticles were then placed on the media, and the plates were incubated for 24 hours at $30^{\circ} \mathrm{C}$. Subsequently, the plates were examined under light and the diameter of the zone of inhibition was measured for each disk using a ruler (Safaei et al., 2019).

\section{Characterization}

The analyses of X-ray diffraction (XRD), Fourier transform infrared spectroscopy (FTIR), and the scanning electron microscopy (SEM) were performed to study the physical and chemical structures of synthesized copper oxide nanoparticles under the five experimental conditions. The XRD analysis was conducted using copper anode in the range of $2 \theta, 20^{\circ}-80^{\circ}$ to determine the type of phases formed and the crystal structure of the nanoparticles. The infrared spectroscopy (FTIR model Brucker Equinox 55, Germany) was used to study the chemical structure and types of bonds. The $\mathrm{CuO}$ nanoparticles were combined with potassium bromide and compacted into a disk; then the sample was scanned in wave range $400-4,000 \mathrm{~cm}^{-1}$ (Das et al., 2016). The morphology and particle size were evaluated using a scanning electron microscope (TESCAN, Czech Republic). The photomicrograph of $\mathrm{CuO}$ nanoparticles was taken with the use of a camera at a voltage of $30 \mathrm{kV}$ with a magnification of $200 \mathrm{~nm}$ (Das et al., 2018).

\section{RESULTS AND DISCUSSION}

Figure 1 shows the FTIR spectrum prepared from the $\mathrm{CuO}$ nanoparticles. The wide peak observed at $3,436 \mathrm{~cm}^{-1}$ is related to the $\mathrm{O}-\mathrm{H}$ group of the surface water adsorbed by copper oxide nanoparticles. The absorption bands in the range of $1,261-1,727 \mathrm{~cm}^{-1}$ can be created as the result of bending vibration of the water molecule or due to the carbonate group via the adsorption of the ambient $\mathrm{CO}_{2}$ by the nanoparticles. The sharp peaks in the 
ranges of $497 \mathrm{~cm}^{-1}$ and $601 \mathrm{~cm}^{-1}$ indicate the vibrations of $\mathrm{Cu}-\mathrm{O}$, which confirm their binding and the synthesis of pure nanoparticles (El-Trass et al., 2012; Srivastava et al., 2010).

The XRD pattern of the $\mathrm{CuO}$ nanoparticles is shown in Figure 2. The XRD pattern prepared from the $\mathrm{CuO}$ nanoparticles was in accordance with the Joint Committee on Powder Diffraction Standards (JCPDS) card no. 45-0937. The $\mathrm{CuO}$ nanoparticles XRD pattern revealed that the synthesized nanoparticles are monoclinic and have a crystal phase. Also, no peak representing impurities was observed in the XRD pattern of the synthesized copper oxide nanoparticles, which suggests the optimal quality of the synthesized nanoparticles (Ahamed et al., 2014).

The morphology and size of $\mathrm{CuO}$ nanoparticles were evaluated using an SEM image, presented in Figure 3. The SEM image showed that the average size of the synthesized nanoparticles was $36 \mathrm{~nm}$, which had been agglomerated in some parts.

The effects of three factors of $\mathrm{CuCl}_{2}, \mathrm{NaOH}$, and stirring time on the rate of antifungal activity of copper oxide nanoparticles synthesized under various experimental conditions designed according to the Taguchi method are shown in Table 1. Based on the results, the nanoparticles synthesized using $\mathrm{CuCl}_{2} 0.1 \mathrm{M}, \mathrm{NaOH}$ $0.1 \mathrm{M}$, and stirring time of 75 minutes (experiment 5) showed the highest fungal growth inhibition rate against $C$. albicans pathogen by $71.72 \%$. In accordance with the results obtained, previous studies also

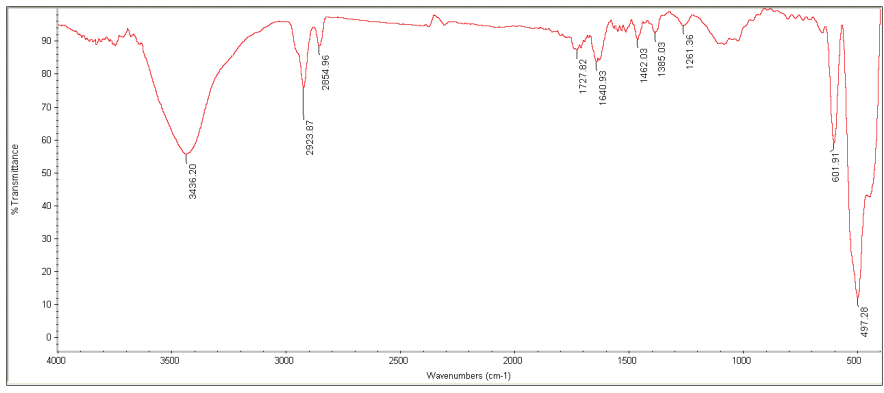

Figure 1. FTIR spectrum of the $\mathrm{CuO}$ nanoparticles.

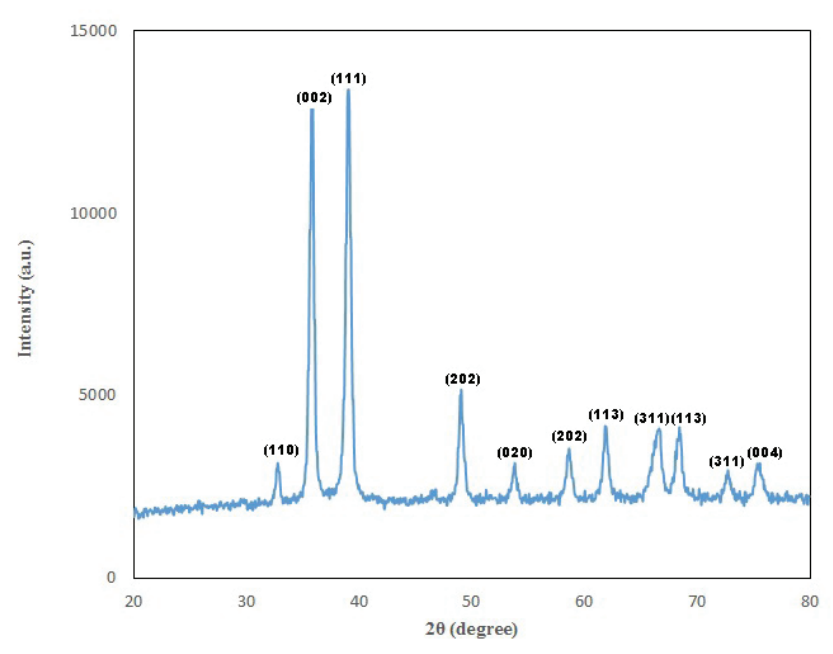

Figure 2. XRD pattern of the $\mathrm{CuO}$ nanoparticles. reported a favorable antifungal activity of copper oxide nanoparticles (Beevi et al., 2012; Devipriya and Roopan, 2017; Weitz et al., 2015). The antimicrobial mechanisms of copper oxide nanoparticles mainly include cell wall destruction, inducing intracellular oxidative stress and dissolution of copper oxide nanoparticles (Dizaj et al., 2014; Ingle et al., 2014). The nanoparticles can damage the fungal cells. The nanoparticles attach to the cell surface and cause structural changes and cell damage. Consequently, they reduce the vital activity of the cell such as permeability, affect the activity of the respiratory chain enzymes and ultimately cause cell death (Roy et al., 2019; Safaei and Taran, 2017b). The copper oxide nanoparticles emit $\mathrm{Cu}^{2+}$ ions, which transform $\mathrm{SH}$ bonds into the microorganisms' walls into the $\mathrm{Cu}-\mathrm{S}$ bonds through the substitution reaction, leading to the destroying of pathogens. The copper oxide nanoparticles and

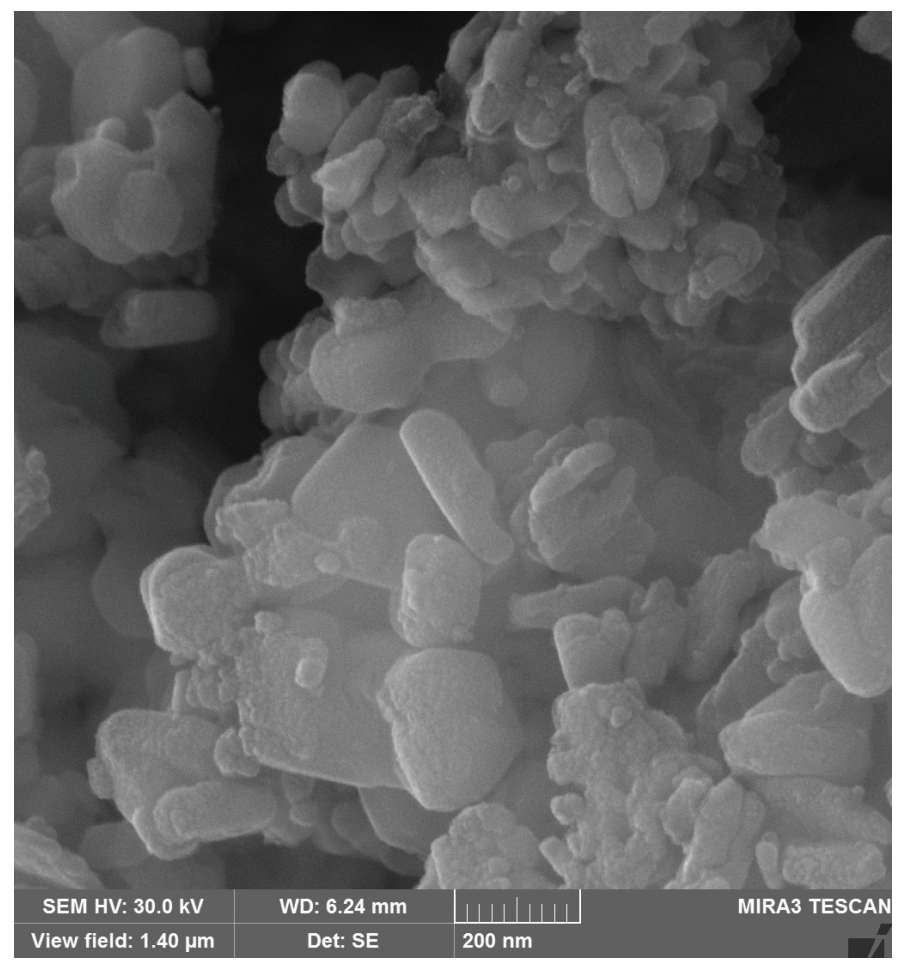

Figure 3. SEM image of the $\mathrm{CuO}$ nanoparticles.

Table 1. Taguchi design of experiments and fungal growth inhibition rate of $\mathrm{CuO}$ synthesized nanoparticles.

\begin{tabular}{|c|c|c|c|c|c|c|c|c|c|c|}
\hline \multirow{2}{*}{ Experiment } & \multicolumn{3}{|c|}{$\mathrm{CuCl2}(\mathrm{M})$} & \multicolumn{3}{|c|}{$\mathrm{NaOH}(\mathrm{M})$} & \multicolumn{3}{|c|}{$\begin{array}{c}\text { Stirring } \\
\text { time(min) }\end{array}$} & \multirow{2}{*}{$\begin{array}{c}\text { Fungal } \\
\text { growth } \\
\text { inhibition } \\
\quad(\%)\end{array}$} \\
\hline & 0.05 & 0.1 & 0.2 & 0.05 & 0.1 & 0.2 & 45 & 60 & 75 & \\
\hline 1 & & 0.05 & & & 0.05 & & & 45 & & 28.02 \\
\hline 2 & & 0.05 & & & 0.1 & & & 60 & & 46.86 \\
\hline 3 & & 0.05 & & & 0.2 & & & 75 & & 31.10 \\
\hline 4 & & 0.1 & & & 0.05 & & & 60 & & 58.31 \\
\hline 5 & & 0.1 & & & 0.1 & & & 75 & & 71.72 \\
\hline 6 & & 0.1 & & & 0.2 & & & 45 & & 53.17 \\
\hline 7 & & 0.2 & & & 0.05 & & & 75 & & 33.19 \\
\hline 8 & & 0.2 & & & 0.1 & & & 45 & & 58.31 \\
\hline 9 & & 0.2 & & & 0.2 & & & 60 & & 66.24 \\
\hline
\end{tabular}


Table 2. The main effects of different levels of $\mathrm{CuCl}_{2}, \mathrm{NaOH}$, and the stirring time on growth inhibition of Candida albicans.

\begin{tabular}{lccc}
\hline Factors & Level 1 & Level 2 & Level 3 \\
\hline $\mathrm{CuCl}_{2}$ & 35.33 & 61.07 & 52.58 \\
$\mathrm{NaOH}$ & 39.84 & 58.96 & 50.17 \\
Stirring time & 46.50 & 57.14 & 45.34 \\
\hline
\end{tabular}

Table 3. The interactions effects of studied factors on growth inhibiting of Candida albicans.

\begin{tabular}{lccc}
\hline Interacting factor pairs & Column & Severity Index (\%) & Optimum conditions \\
\hline $\mathrm{NaOH} \times$ Stirring time & $2 \times 3$ & 47.75 & {$[2,3]$} \\
$\mathrm{CuCl}_{2} \times$ Stirring time & $1 \times 3$ & 15.67 & {$[2,3]$} \\
$\mathrm{CuCl}_{2} \times \mathrm{NaOH}$ & $1 \times 2$ & 6.21 & {$[2,2]$} \\
\hline
\end{tabular}

Table 4. The analysis of variance of factors affecting the growth inhibition of Candida albicans.

\begin{tabular}{lcccccc}
\hline Factors & DOF & $\begin{array}{c}\text { Sum of } \\
\text { Squares }\end{array}$ & Variance & F-Ratio (F) & $\begin{array}{c}\text { Pure } \\
\text { Sum }\end{array}$ & Percent (\%) \\
\hline $\mathrm{CuCl}_{2}$ & 2 & 1032.25 & 516.12 & 5.74 & 852.59 & 42.30 \\
$\mathrm{NaOH}$ & 2 & 549.73 & 274.87 & 3.06 & 370.08 & 18.36 \\
Stirring time & 2 & 253.73 & 126.87 & 1.41 & 74.08 & 3.67 \\
\hline
\end{tabular}

$\mathrm{DOF}=$ degree of freedom.

Table 5. The optimum conditions for the synthesis of $\mathrm{CuO}$ nanoparticles with the highest antifungal activity.

\begin{tabular}{lcc}
\hline Factors & Level & Contribution \\
\hline $\mathrm{CuCl}_{2}$ & 2 & 11.41 \\
$\mathrm{NaOH}$ & 2 & 9.30 \\
Stirring time & 2 & 7.48 \\
Total contribution from all factors & & 28.19 \\
Current grand average of performance & 49.66 \\
Fungal growth inhibition at optimum condition & 77.85 \\
\hline
\end{tabular}

Table 6. The antifungal activity of synthesized $\mathrm{CuO}$ nanoparticles in optimal conditions proposed by Taguchi method.

\begin{tabular}{lc}
\hline Type of assay & Candida albicans pathogen \\
\hline Fungal growth inhibition (\%) & 77.06 \\
Zone of inhibition (mm) & 15.33 \\
\hline
\end{tabular}

extracellular $\mathrm{Cu}^{2+}$ cross the cell membrane through endocytosis and copper-transferring proteins, respectively, and enter the cytoplasm and destroy the fungi. By increasing the concentration of copper oxide nanoparticles, their penetration increases into the cytoplasm, resulting in a higher level of pathogen losses (Hou et al., 2017).

Table 2 shows the effects of each of the factors of $\mathrm{CuCl}_{2}$, $\mathrm{NaOH}$, and stirring time at different levels on the rate of antifungal activity of copper nanoparticles. All examined factors were effective on the antifungal activity rate of nanoparticles against the C. albicans pathogen. The factors of $\mathrm{CuCl}_{2}, \mathrm{NaOH}$, and stirring time represented their highest performance rate at the second level, respectively, as $61.07,58.96$, and 57.14 . The interaction effect among $\mathrm{CuCl}_{2}, \mathrm{NaOH}$, and stirring time and their impacts on the antifungal activity of the synthesized nanoparticles are given in Table 3. The range of interaction effect of the examined factors varied from 47.75 to 6.21 . The $\mathrm{NaOH} \times$ Stirring time and $\mathrm{CuCl}_{2} \times \mathrm{NaOH}$ had the highest and lowest interaction effect as 47.75 and 6.21 , respectively.

The analysis of variance results of the factors effective in optimizing the synthesis of copper oxide nanoparticles is presented in Table 4. All three factors of $\mathrm{CuCl}_{2}, \mathrm{NaOH}$, and stirring time were effective on the antifungal activity rate of copper oxide nanoparticles. The factors of $\mathrm{CuCl}_{2}$ and stirring time had the highest and lowest effects on the synthesis of copper oxide nanoparticles with the most optimal antifungal activity as 42.30 and 3.67 , respectively.

The proposed conditions based on the Taguchi method for the synthesis of copper oxide nanoparticles with the best antifungal activity are presented in Table 5. According to the results, all three factors of $\mathrm{CuCl}_{2}, \mathrm{NaOH}$ and stirring time at the second level showed the greatest effect in the synthesis of copper oxide nanoparticles with the highest antifungal activity. The factors of $\mathrm{CuCl}_{2}$ and stirring time showed, respectively, the highest (11.41) and lowest (7.48) effect in improving the antifungal performance of the synthesized nanoparticles.

Table 6 shows the rate of antifungal activity of the copper oxide nanoparticles synthesized under the proposed optimum conditions against $C$. albicans pathogen. Evaluating the antifungal effect of synthesized copper oxide nanoparticles by the CFU method indicated a decrease in the growth of $C$. albicans pathogen by 77.06. In the disk diffusion method, the amount of inhibition zone for C. albicans pathogen was 15.33 , which was consistent with the results of the CFU method and confirmed the optimal antifungal activity of the synthesized copper oxide nanoparticles.

\section{CONCLUSION}

Characterization of nanoparticles by FTIR, XRD, and SEM analyses confirmed the synthesis of nanoparticles with appropriate structure and size. The synthesized nanoparticles under the proposed conditions by the Taguchi method showed desirable and similar antifungal results in both the CFU and disk diffusion methods. Thus, they can be used alone or combined with other substances as an appropriate alternative instead of conventional antimicrobial compounds to fight against the drug resistance of pathogens and the increased risk of the spread of oral infections. However, we should be careful in using them according to some reports on the toxicity of high concentrations of copper oxide nanoparticles.

\section{FINANCIAL SUPPORT}

None.

\section{CONFLICT OF INTEREST}

Authors declare that there are no conflicts of interest.

\section{REFERENCES}

Ahamed M, Alhadlaq HA, Khan MA, Karuppiah P, Al-Dhabi NA. Synthesis, characterization, and antimicrobial activity of copper oxide nanoparticles. J Nanomater, 2014; 2014:637858.

Beevi MH, Vignesh S, Pandiyarajan T, Jegatheesan P, James RA, Giridharan NV, Karthikeyan B. Synthesis and antifungal studies on $\mathrm{CuO}$ nanostructures. Adv Mater Res, 2012; 488:666-70.

Cura F, Palmieri A, Girardi A, Martinelli M, Scapoli L, Carinci F. Lab-Test 4: Dental caries and bacteriological analysis. Dent Res J, 2012; 9(2):139-141. 
Das SK, Kahali N, Bose A, Khanam J. Physicochemical characterization and in vitro dissolution performance of ibuprofenCaptisol ${ }^{\circledR}$ (sulfobutylether sodium salt of $\beta-C D$ ) inclusion complexes. J Mol Liq, 2018; 261:239-49.

Das SK, Khanam J, Nanda A. Optimization of preparation method for ketoprofen-loaded microspheres consisting polymeric blends using simplex lattice mixture design. Mater Sci Eng C, 2016; 69:598-608.

Devipriya D, Roopan SM. Cissus quadrangularis mediated ecofriendly synthesis of copper oxide nanoparticles and its antifungal studies against Aspergillus niger, Aspergillus flavus. Mater Sci Eng C, 2017; 80:38-44.

Dizaj SM, Lotfipour F, Barzegar-Jalali M, Zarrintan MH, Adibkia K. Antimicrobial activity of the metals and metal oxide nanoparticles. Mater Sci Eng C, 2014; 44:278-84.

El-Trass A, ElShamy H, El-Mehasseb I, El-Kemary M. CuO nanoparticles: synthesis, characterization, optical properties and interaction with amino acids. Appl Surf Sci, 2012; 258(7):2997-3001.

Fallahi A, Ghofranipour F, Ahmadi F, Malekafzali B, Hajizadeh E. Challenges of Iranian adolescents for preventing dental caries. Iran Red Crescent Med J, 2014; 16(9):15009.

Farges JC, Alliot-Licht B, Renard E, Ducret M, Gaudin A, Smith AJ, Cooper PR. Dental pulp defence and repair mechanisms in dental caries. Mediators Inflamm, 2015; 2015:230-51.

Frencken JE, Sharma P, Stenhouse L, Green D, Laverty D, Dietrich T. Global epidemiology of dental caries and severe periodontitis-a comprehensive review. J Clin Periodontol, 2017; 44:94-105.

Goes P, Dutra CS, Lisboa MR, Gondim DV, Leitão R, Brito GA, Rego RO. Clinical efficacy of a 1\% Matricaria chamomile L. mouthwash and $0.12 \%$ chlorhexidine for gingivitis control in patients undergoing orthodontic treatment with fixed appliances. J Oral Sci, 2016; 58(4):569-74.

Hou J, Wang X, Hayat T, Wang X. Ecotoxicological effects and mechanism of $\mathrm{CuO}$ nanoparticles to individual organisms. Environ Pollut, 2017; 221:209-17.

Ingle AP, Duran N, Rai M. Bioactivity, mechanism of action, and cytotoxicity of copper-based nanoparticles: a review. Appl Microbiol Biotechnol, 2014; 98(3):1001-9.

Lanje AS, Sharma SJ, Pode RB, Ningthoujam RS. Synthesis and optical characterization of copper oxide nanoparticles. Adv Appl Sci Res, 2010; 1(2):36-40.

Mozaffari HR, Izadi B, Sadeghi M, Rezaei F, Sharifi R, Jalilian F. Prevalence of oral and pharyngeal cancers in Kermanshah province, Iran: a ten-year period. Int J Cancer Res, 2016;12(3-4):169-75.

Mozaffari HR, Payandeh M, Ramezani M, Sadeghi M, Mahmoudiahmadabadi M, Sharifi R. Efficacy of palifermin on oral mucositis and acute GVHD after hematopoietic stem cell transplantation (HSCT) in hematology malignancy patients: a meta-analysis of trials. Wspolczesna Onkol, 2017; 21(4):299-305.

Mozaffari HR, Zavattaro E, Abdolahnejad A, Lopez-Jornet P, Omidpanah N, Sharifi R, Sadeghi M, Shooriabi M, Safaei M. Serum, and Salivary $\operatorname{IgA}, \mathrm{IgG}$, and $\operatorname{IgM}$ levels in oral lichen planus: a systematic review and meta-analysis of case-control studies. Medicina, 2018; 54(6):99.

Petersen PE, Bourgeois D, Ogawa H, Estupinan-Day S, Ndiaye C. The global burden of oral diseases and risks to oral health. Bull World Health Organ, 2005; 83:661-9.
Roy A, Bulut O, Some S, Mandal AK, Yilmaz MD. Green synthesis of silver nanoparticles: biomolecule-nanoparticle organizations targeting antimicrobial activity. RSC Adv, 2019; 9(5):2673-702.

Safaei M, Karimi N, Alavi M, Taran M. Application of nanomaterial in nutrition and food sciences. J Adv Appl Sci Res, 2017; $1(12): 1-6$

Safaei M, Taran M, Imani MM. Preparation, structural characterization, thermal properties and antifungal activity of alginate- $\mathrm{CuO}$ bionanocomposite. Mater Sci Eng C, 2019; 101:323-9.

Safaei M, Taran M. Fabrication, characterization, and antifungal activity of sodium hyaluronate- $\mathrm{TiO} 2$ bionanocomposite against Aspergillus niger. Mater Lett, 2017a; 207:113-6.

Safaei M, Taran M. Optimal conditions for producing bactericidal sodium hyaluronate- $\mathrm{TiO} 2$ bionanocomposite and its characterization. Int $\mathrm{J}$ Biol Macromol, 2017b; 104:449-56.

Sata T, Sata T, Yang W. Studies on cation-exchange membranes having permselectivity between cations in electrodialysis. J Membrane Sci, 2002; 206(1):31-60.

Sharifi R, Khazaei S, Mozaffari HR, Amiri SM, Iranmanesh P, Mousavi SA. Effect of massage on the success of anesthesia and infiltration injection pain in maxillary central incisors: Double-blind, crossover trial Dent Hypotheses, 2017; 8(3):61-4.

Srivastava M, Ojha AK, Chaubey S, Sharma PK, Pandey AC. Influence of calcinations temperature on physical properties of the nanocomposites containing spinel and $\mathrm{CuO}$ phases. J Alloy Compd, 2010; 494(1):275-84

Struzycka IZ. The oral microbiome in dental caries. Pol J Microbiol, 2014; 63(2):127-35.

Weitz IS, Maoz M, Panitz D, Eichler S, Segal E. Combination of $\mathrm{CuO}$ nanoparticles and fluconazole: preparation, characterization, and antifungal activity against Candida albicans. J Nanopart Res, 2015; 17(8):342

Zhang L, Jiang Y, Ding Y, Povey M, York D. Investigation into the antibacterial behaviour of suspensions of $\mathrm{ZnO}$ nanoparticles ( $\mathrm{ZnO}$ nanofluids). J Nanopart Res, 2007; 9(3):479-89.

Zhu Y, Liao L. Applications of nanoparticles for anticancer drug delivery: a review. J Nanosci Nanotechnol, 2015; 15(7):4753-73.

\section{How to cite this article:}

Imani MM, Safaei M, Moradpoor H, Rezaei R, Golshah A, Rezaei F, Jamshidy L. Optimum synthesis of $\mathrm{CuO}$ nanoparticles with the highest antifungal activity against oral pathogen Candida albicans. J Appl Pharm Sci, 2020; 10(02):021-025. 